\title{
INOCULACIÓN DE VAINITA (Phaseolus vulgaris L.) CON DIFERENTES CONCENTRACIONES DE Rhizobium etli Y SU INFLUENCIA SOBRE EL RENDIMIENTO DEL CULTIVO
}

\section{INOCULATION OF GREEN BEANS (Phaseolus vulgaris L.) WITH DIFFERENT CONCENTRATIONS OF Rhizobium etli AND ITS INFLUENCE ON CROP YIELD}

\author{
Virginia Chipana ${ }^{1}$, Claudia Clavijo ${ }^{2}$, Paul Medina ${ }^{3}$ y Daladier Castillo ${ }^{4}$
}

\begin{abstract}
Resumen
El cultivo de vainita está bastante difundido en la costa sur peruana que tiene características desérticas. Se trabajó a nivel de laboratorio, para producir el inoculante y aplicarlo en campo, mediante un diseño en bloques completamente aleatorizado. Los tratamientos fueron: inoculante 2.5 $\times 10^{7} \mathrm{cel} \mathrm{g}^{-1}$ suelo, $2.5 \times 10^{8} \mathrm{cel} \mathrm{g}^{-1}$ suelo, $2.5 \times 10^{9} \mathrm{cel} \mathrm{g}^{-1}$ suelo, control negativo agua destilada, testigo fertilizado y testigo biológico. Se cuantificó el número de nódulos por planta y el porcentaje de nódulos efectivos por planta. En cada cosecha se determinó el rendimiento por hectárea, rendimiento por planta, longitud de vaina, peso de vaina y número de vainas por planta. Se determinó la influencia de la inoculación con diferentes concentraciones de Rhizobium etli sobre el rendimiento de este cultivo. El tratamiento inoculado con una concentración de $2.5 \times 10^{9} \mathrm{cel} \mathrm{g}^{-1}$ suelo generó el mayor número de nódulos totales con un promedio de $47.67 \mathrm{y}$ con una efectividad de $84.02 \%$. Este tratamiento produjo una mayor influencia en el rendimiento por hectárea, rendimiento por planta y número de vainas por planta, al mismo tiempo que no tuvo diferencia significativa al ser comparado con el testigo fertilizado.
\end{abstract}

Palabras clave: rizobio, cepa, vaina, inoculante, nódulos y nitrógeno.

\begin{abstract}
The green bean crop is fairly widespread in the Peruvian southern coast which has desert features. At the laboratory level, we worked to produce the inoculant and to apply it in the field through a completely randomized blocks design. The treatments were the following: inoculant 2.5 x $10^{7}$ cel g ${ }^{-1}$ soil, $2.5 \times 10^{8} \mathrm{cel} \mathrm{g}^{-1}$ soil, $2.5 \times 10^{9} \mathrm{cel} \mathrm{g}^{-1}$ soil, distilled water as a negative control, a fertilized and a biological control. The number of nodules per plant and percentage of effective nodules per plant were quantified. In each harvest the yield per hectare, per plant, the pod length and weight and the number of pods per plant were determined. The influence of inoculation with different concentrations of Rhizobium etli on the yield of this crop was determined. The inoculated treatment with a concentration of $2.5 \times 10^{9} \mathrm{cel} \mathrm{g}^{-1}$ soil generated the largest number of total nodules with an average of 47.67 and an effectiveness of $84.02 \%$. This treatment produced a higher influence on the yield per hectare and per plant and the number of pods per plant, but it did not have a significant difference when it was compared with the fertilized control.
\end{abstract}

Key words: rhizobia, strain, pod, inoculant, nodules and nitrogen.

\section{Introducción.}

Aproximadamente el $85 \%$ de la fijación de nitrógeno en la tierra tiene un origen biológico. En la fijación de nitrógeno, éste se reduce a amoniaco que es convertido en forma orgánica, esta actividad es característica de algunos procariotas. Bacterias como los rizobios pueden hacer simbiosis con las raíces de plantas leguminosas, formar nódulos radicales y realizar la fijación biológica de nitrógeno (Madigan et al., 2000).

La fijación biológica de nitrógeno es un proceso natural e importante dentro de la agricultura mundial. Los cálculos globales estimados en cuanto a esta fijación, específicamente relacionadas a la simbiosis entre los rizobios y los cultivos de leguminosas son alrededor de 20-22 millones de toneladas de nitrógeno por año (Herridge et al., 2008). La mayor parte del nitrógeno fijado por las leguminosas es retirado durante la cosecha, siendo las semillas las que presentan un alto valor proteico. Sin embargo, es conocido también que el cultivo de leguminosas mejora la productividad en cultivos posteriores, debido a una mejor disponibilidad de nitrógeno en los suelos (Peoples et al., 2009).

La aplicación de fertilizantes químicos afecta negativamente a la fertilidad de suelos en todo el mundo; para resolver este problema es importante aplicar prácticas integradas y así lograr un manejo sustentable en la agricultura. La promoción y el 
desarrollo de biofertilizantes pueden representar una herramienta para resolver este problema. Los biofertilizantes microbianos son comúnmente conocidos como Rizobacterias Promotoras del Crecimiento Vegetal (PGPRs, por su acrónimo en inglés) (Bharti et al., 2015).

Se realizaron aislamientos de rizobios en varios lugares del mundo y gracias al avance en técnicas de biología molecular, nuevas especies fueron descritas como simbiontes del frejol común. Así como también, especies de rizobios como $R$. etli, $R$. phaseoli y $R$. leguminosarum forman nódulos en frejol común $\mathrm{y}$ demostraron ser efectivas en la fijación de nitrógeno (Aserse et al., 2012).

La inoculación con Rhizobium y estiércol de granja sería beneficiosa en leguminosas de grano al mejorar la productividad, tanto en la nodulación como en el rendimiento; esto trasciende a pequeños agricultores que no utilizan fertilizantes inorgánicos (Otieno et al., 2009). Así también Deaker et al. (2004) refieren que la inoculación resulta ser un método eficiente y adecuado, se pueden introducir cepas eficaces de rizobios al suelo y de allí a la rizósfera, varios estudios demostraron aumentos en el rendimiento de hasta en un $25 \%$. La aplicación del inoculante de $R$. tropici con $\mathrm{Co}+\mathrm{Mo}$ pulverizado foliarmente podría sustituir la fertilización mineral nitrogenada en frejol en una concentración de $1 \times 10^{8} \mathrm{cel} \mathrm{g}^{-1}$ (Berton et al., 2008).

Los estándares en la concentración de inoculantes varían de acuerdo al lugar de origen y están en el rango de $5 \times 10^{7}$ a 1 x $10^{9}$ cel $\mathrm{mL}^{-1}$ en inoculantes recién preparados (Lupwayi et al., 2000), así como también Albareda et al. (2008) utilizaron concentraciones para pruebas en campo entre $10^{8}-10^{10}$ unidades formadoras de colonias (UFC) $\mathrm{mL}^{-1}$.

El frejol común (P. vulgaris L.) es una leguminosa que es infectada por bacterias fijadoras de nitrógeno conocidas como rizobios que forman nódulos radicales. La domesticación de esta leguminosa ocurrió hace varios miles de años en Mesoamérica y la Región de los Andes (Rodiño et al., 2010). Esta hortaliza es una de las leguminosas de grano más importantes en todo el mundo (Beebe et al., 2001). Peoples \& Herridge (1990) indican que esta simbiosis es trascendente en países en vías de desarrollo, donde la agricultura está propensa a pérdidas de nitrógeno y las leguminosas representan una fuente alterna de proteínas para el consumo humano y animal.

En el Perú, la superficie anual cosechada de vainita es de 2381 ha, con una producción anual de 16840 t de esta hortaliza. En Tacna se tienen 227 ha de superficie cosechada y una producción anual de vainita de 1603 t (Ministerio de Agricultura y Riego, 2014).

En Tacna no se han realizado trabajos con biofertilización utilizando diferentes concentraciones de inoculante $R$. etli en vainita, y no se conocen las dosis adecuadas para su aplicación en campo que permitan un rendimiento atractivo para el agricultor.
Este estudio procura brindar una alternativa de solución con la aplicación del inoculante en la dosis adecuada en cultivos de vainita, cuyos resultados puedan contribuir a la disminución de la fertilización química nitrogenada. Por tanto, el objetivo de esta investigación fue determinar la influencia de la inoculación con diferentes concentraciones de $R$. etli sobre el rendimiento del cultivo de vainita.

\section{Materiales y métodos.}

Ubicación geográfica y características edafoclimáticas del sitio experimental.

Este estudio se realizó en el Instituto de Investigación, Producción y Extensión Agraria (INPREX) de la Universidad Nacional Jorge Basadre Grohmann, ubicado en la Provincia de Tacna, Región Tacna, Perú (latitud sur $18^{\circ} 01^{\prime} 49.98^{\prime}$ y longitud oeste $70^{\circ} 15^{\prime} 12.54$ " y $538 \mathrm{~m} \mathrm{s.} \mathrm{n.} \mathrm{m.).} \mathrm{El} \mathrm{cultivo} \mathrm{tuvo} \mathrm{una}$ duración de 91 días y fue entre los meses de marzo a junio del año 2014 , la temperatura máxima media fue de $27.3^{\circ} \mathrm{C}$ y la mínima de $11.5^{\circ} \mathrm{C}$, con una humedad relativa mínima de $73 \%$ y una máxima de $85 \%$ (SENAMHI, 2014). El suelo del sitio experimental presentó una textura franca, un contenido bajo de materia orgánica $(1.20 \%), \mathrm{pH}$ ligeramente alcalino (7.54), un nivel bajo de nitrógeno $(0.07 \%)$, un valor medio de fósforo (13.3 ppm) y un contenido de potasio alto (1 124 ppm). Tanto las muestras de suelo y biol se analizaron en el Laboratorio de Análisis de Suelos, Plantas, Aguas y Fertilizantes de la Universidad Nacional Agraria La Molina.

Pruebas de pureza, caracterización fenotípica y producción de inoculante de la cepa de R. etli 188-03.

Para esta investigación se contó con la cepa de $R$. etli 188-03, cedida por el Laboratorio de Microbiología Ambiental de la Universidad Nacional de Trujillo, Perú. La cepa se reactivó en el medio Levadura Manitol Agar con Rojo Congo, se hizo la coloración Gram que correspondió a bacilos gramnegativos asporógenos (Vincent, 1970). Las pruebas de pureza fueron:

Crecimiento en el medio Agar Levadura Lactosa: se sembró el cultivo aislado por duplicado en placas con medio ALL por estrías paralelas, se incubó a $28^{\circ} \mathrm{C}$ por 2 días (para Rhizobium sp.). Al observar el crecimiento bacteriano se adicionó $5 \mathrm{ml}$ del reactivo de Benedict e incubó a temperatura ambiente por 10 minutos, se evaluó el cambio de color, que indicó la producción de $\alpha$ cetolactolasa, característico de Agrobacterium y no de rizobios, éstos últimos no producen un cambio de color del reactivo (CIAT, 1988).

Crecimiento en el medio Peptona-Glucosa con el Indicador Púrpura de Bromocresol: se sembró por duplicado el cultivo en este medio mediante estrías paralelas, e incubó a $28^{\circ} \mathrm{C}$ por 2 días (para Rhizobium sp.). Se observó el crecimiento y cambio de coloración, un buen crecimiento de la bacteria con un cambio de color del medio, no corresponde a los rizobios ya que 
éstos no desarrollan bien en este medio y probablemente sea un contaminante (CIAT, 1988).

Crecimiento en el medio Luria Bertani: se sembró por duplicado el cultivo en medio LB mediante estrías paralelas, se incubó a $28^{\circ} \mathrm{C}$ por 2 días. Al igual que en el medio anterior, un buen crecimiento de la bacteria no corresponde a los rizobios, por lo que probablemente sea un contaminante, aunque se ha observado excepcionalmente el crecimiento de cepas de $R$. tropici de frijol (CIAT, 1988).

Asimismo, se realizó la prueba de caracterización fenotípica como la Producción de ácido o álcali en Agar Extracto de Levadura Azul de Bromotimol al 0,5\%: se sembró la cepa de Rhizobium en forma de $\mathrm{S}$ en dicho medio, se incubó a $28^{\circ} \mathrm{C}$ por 3 a 7 días. Si no hay cambio el medio es neutro, azul indica alcalinidad (cepas de crecimiento lento), amarillo indica acidez (cepas de crecimiento rápido), los resultados agrupan a los rizobios como productores de ácido o álcali (Ferrera-Cerrato et al., 1993).

Todas estas pruebas realizadas calificaron a la cepa como pura y de crecimiento rápido con producción de acidez.

Para la producción del inoculante líquido se utilizó el Caldo Levadura Manitol, al biorreactor se le inyectó aire purificado, se incubó a $28^{\circ} \mathrm{C}$ (Vincent, 1970), se hicieron conteos directos por cámara de Neubauer y se obtuvo un conteo aproximado de $10^{9}$ cel $\mathrm{mL}^{-1}$ a las 46 horas (fase exponencial).

Biol.

Se empleó biol de fabricación casera como testigo biológico, abono orgánico, biofertilizante y biostimulante para el crecimiento vegetal; se utilizó un bidón de plástico de $60 \mathrm{~L}$, la composición fue: $25 \mathrm{~L}$ de agua no clorada, $20 \mathrm{Kg}$ de estiércol fresco de vaca, 2 tapas de chancaca, 2 tazas de concho de chicha, $1 \mathrm{Kg}$ de ceniza de leña, $1 \mathrm{~L}$ de leche, $1 / 2 \mathrm{Kg}$ de cáscara de huevo molido y $2 \mathrm{Kg}$ de hojas picadas de alfalfa, se dejó fermentar por 2 meses.

Diseño experimental.

Para el análisis estadístico se usó el diseño experimental de bloques completamente aleatorizado, con seis tratamientos y tres repeticiones.

Establecimiento y manejo agronómico del experimento.

Los tratamientos fueron: inoculante $2.5 \times 10^{7}$ cel g${ }^{1}$ suelo (200 g de suelo en $30 \mathrm{~kg}$ de semilla), inoculante $2.5 \times 10^{8}$ cel g$^{-1}$ suelo (200 $\mathrm{g}$ de suelo en $30 \mathrm{~kg}$ de semilla), inoculante $2.5 \times 10^{9} \mathrm{cel} \mathrm{g}^{-1}$ suelo (200 $\mathrm{g}$ de suelo en $30 \mathrm{~kg}$ de semilla), control negativo agua destilada, testigo fertilizado y testigo biológico.

Se consideró como referencia la dosis de fertilización 70-80-80 NPK. Se adicionó una pequeña cantidad de nitrógeno mineral a razón de $30 \mathrm{~kg} \mathrm{~N}^{-1}$ (Silvester, 1983) a todos los tratamientos en forma de fosfato diamónico. Se fertilizaron todos los tratamientos durante la siembra, se aplicó a cada uno: $173.90 \mathrm{~kg} \mathrm{ha}^{-1}$ de fosfato diamónico y $34.00 \mathrm{~kg} \mathrm{ha}^{-1} \mathrm{de}$ sulfato de potasio, pero al tratamiento testigo fertilizado se le adicionó un fertilizante más como la urea a razón de $84.10 \mathrm{~kg} \mathrm{ha}^{-1}$ (1/3 durante la siembra y $2 / 3$ restantes antes de la floración). La fertilización se realizó de manera uniforme cercana a las semillas, y luego se cubrieron con una capa de suelo.

La unidad experimental correspondió a un área de 6 $\mathrm{m}^{2}$, la distancia entre líneas fue de $1 \mathrm{~m}$ y entre plantas se consideró $0.2 \mathrm{~m}$. El suelo se preparó secuencialmente, se utilizó arado y rastra de discos, se removió el suelo a una profundidad aproximada de 0.35 $\mathrm{m}$ con el fin de conseguir una buena porosidad, se abrieron surcos de siembra manualmente, se agregó estiércol de corral de vacuno a razón de 10 t ha- ${ }^{-1}$. Se usó como método de siembra, la siembra directa, las semillas se distribuyeron en cada golpe a una distancia de $0.2 \mathrm{~m}$, las cuales se cubrieron con $2-3 \mathrm{~cm}$ de tierra; se empleó la semilla de vainita que correspondió a la var. Jade (Syngenta Rogers). Las semillas, a excepción de las que correspondieron a los tratamientos testigo fertilizado y testigo biológico, se lavaron varias veces con agua corriente hasta eliminar el antifúngico.

En los tratamientos con inoculación se aplicó el inoculante líquido a razón de $50 \mathrm{~mL} 30 \mathrm{~kg}$ de semilla mezclados con $200 \mathrm{~g}$ de suelo, se agregó bajo la sombra y se procedió a sembrar (Zúñiga, 2012). En el testigo biológico la aplicación de biol fue foliar al $10 \%$ a los 15, 22 y 30 días después de la siembra, similar a la metodología de Barrios \& Siura (1999).

Los deshierbos (control de malezas) se hicieron durante todo el ciclo de crecimiento para mantener al área libre de malezas, se realizó un control integrado de plagas y enfermedades. Asimismo, como preventivo se aplicó el fungicida Farmathe (ingrediente activo Benomyl) al día siguiente de la siembra e inmediatamente después de la germinación, el método de aplicación fue en la superficie del suelo, similar a la metodología de Kloepper et al. (2012).

Se utilizó un riego por goteo, que fue ligero, con una frecuencia de tres veces por semana; el volumen de agua utilizado fue de $4095 \mathrm{~m}^{3} \mathrm{ha}^{-1}$. La primera cosecha se efectuó a los 60 días después de la siembra (DDS), se realizaron en total cinco cosechas en forma manual. Evaluación a inicios de la formación de vainas (45 DDS).

Para el número de nódulos por planta, de cada unidad experimental se tomaron tres plantas y en cada una se contó el número total de nódulos presentes en las raíces. En cuanto al porcentaje de nódulos efectivos o activos por planta, de los nódulos totales contados, se hicieron cortes transversales, se clasificaron como nódulos efectivos los que fueron descritos de color rosado en su interior y nódulos inactivos los descritos de color blanco (Frioni, 1999; Chmelíková \& Hejcman, 2012).

Evaluaciones a cosecha (60 DDS).

Se consideró el rendimiento $\left(\mathrm{kg} \mathrm{ha}^{-1}\right)$, se eligieron al azar 10 plantas por cada unidad experimental; para el 
rendimiento $\left(\mathrm{g} \mathrm{planta}^{-1}\right)$ se tomaron 10 plantas en forma aleatoria por cada unidad experimental; la longitud de vaina $(\mathrm{cm})$ se consideraron en forma aleatoria 10 plantas por cada unidad experimental que equivale al $33.33 \%$ del total de la unidad, de las que se eligió para medir una vaina al azar de cada planta; peso de vaina (g) se escogieron en forma aleatoria 10 plantas por cada unidad experimental, se pesó el total de vainas de cada planta, se obtuvo un promedio; y en el número de vainas por planta $\left(\mathrm{N}^{\circ}\right)$ se evaluaron 10 plantas al azar por cada unidad experimental.

Análisis de datos.

La colección de datos obtenidos se procesó estadísticamente, se usó el análisis de varianza (ANVA) y prueba de rango múltiple de Duncan $(\mathrm{P}<0.05)$ para comparación de medias e identificar diferencias significativas entre tratamientos. Para procesar los análisis se empleó el software Statgraphics Centurion XVI.I (Statpoint Technologies, 2010).

\section{Resultados y discusión.}

Número de nódulos por planta.

En la Tabla 1 el tratamiento inoculante $2.5 \times 10^{9} \mathrm{cel}$ $\mathrm{g}^{-1}$ suelo fue significativamente diferente al resto de tratamientos con inoculación, ya que presentó el mayor promedio en el número de nódulos que fue 47.67; la inoculación incrementó el número de nódulos por planta, los tratamientos con menores concentraciones también presentaron nódulos, pero no fueron suficientes estas concentraciones para producir una diferencia. En los tratamientos que no fueron inoculados, se observaron nódulos en los pelos radicales de las plantas, esto es similar a lo informado por Pelegrin et al. (2009) que encontraron nódulos en plantas de frejol que no fueron inoculadas con Rhizobium ni tampoco recibieron nitrógeno mineral. Por lo evidenciado en el trabajo, esto indica la presencia de rizobios nativos simbiontes para $P$. vulgaris $\mathrm{L}$.

En los tratamientos con concentraciones menores de inóculo, las variables ambientales en las que se desarrolló el experimento pudieron influenciar de manera indirecta sobre la nodulación, ya que el rango óptimo de temperatura para formación de nódulos se encuentra entre 18 y $29^{\circ} \mathrm{C}$, y las mínimas estuvieron en los primeros meses en 15.8 y $15.3^{\circ} \mathrm{C}$ (SENAMHI,

Tabla 1. Promedio del número de nódulos por planta para diferentes tratamientos aplicados en vainita variedad Jade.

\begin{tabular}{lc}
\hline Tratamiento & Número de nódulos por planta \\
\hline $2.5 \times 10 \mathrm{E} 7$ cel g suelo & $4.17 \mathrm{a}$ \\
$2.5 \times 10 \mathrm{E} 8$ cel g suelo & $5.54 \mathrm{a}$ \\
$2.5 \times 10 \mathrm{E} 9$ cel g suelo & $47.67 \mathrm{~b}$ \\
Control negativo & $3.25 \mathrm{a}$ \\
Testigo fertilizado & $10.5 \mathrm{a}$ \\
Testigo biológico & $5.34^{\mathrm{a}}$ \\
\hline Valores sin letras en común son significativamente \\
diferentes $(\mathrm{p}<0.05)$.
\end{tabular}

2014). También se tiene que el exceso de sal, altos niveles de nitrógeno combinado pueden afectar la nodulación, entre otros (Grant \& Long, 1989). Por otro lado, en la aplicación del inoculante líquido con suelo a las semillas durante la siembra, no se utilizó en el caldo de cultivo un aditivo que hubiera permitido una mayor adhesión de las bacterias a las semillas.

Cabe señalar que la aplicación del fungicida Farmathe (Benomyl) después de la siembra, no fue directamente en las semillas, sino en el suelo, esto pudiera tener un efecto en la disminución de la nodulación. Mårtensson (1992) encontró que la deformación de los pelos radicales inducida por los rizobios, necesaria para la nodulación, tuvo una disminución en presencia de Benomyl. Además, sugiere tener cautela al interpretar resultados de laboratorio y campo en el uso de químicos en la agricultura, aunque las bacterias pueden persistir contra la mayoría de ellos, hay indicios que la eficiencia simbiótica puede ser alterada.

Silvester (1983) indica que la disponibilidad de N proveniente de la fijación biológica se inicia aproximadamente a los 20 días después de la siembra, por eso es necesario aplicar una reducida cantidad de nitrógeno mineral (30 $\left.\mathrm{kg} \mathrm{N} \mathrm{ha}^{-1}\right)$, para estimular el crecimiento inicial de las plántulas, favorecer el establecimiento de cepas en el cultivo y la formación de nódulos.

En sistemas hidropónicos se inoculó $R$. etli ISP42 ( 1 x $10^{5}$ UFC $\mathrm{mL}^{-1}$ ) en $P$. vulgaris 'Negro Jamapa' y se obtuvieron $9 \pm 3$ nódulos por planta (Dardanelli et al., 2008). R. tropici 10813 y $10716\left(10^{9} \mathrm{cel} \mathrm{g}^{-1}\right.$ de turba y $500 \mathrm{~g}$ de turba para $50 \mathrm{~kg}$ de semilla) tuvieron $16.8 \mathrm{y}$ 12.8 nódulos, respectivamente, cuando se le aplicó como estímulo para la nodulación $\mathrm{N}$ mineral a razón de $40 \mathrm{~kg} \mathrm{ha}^{-1}$ en la siembra de frejol Carioca (Otsubo et al., 2013), esta concentración es aproximada a la dosis aplicada en el tratamiento inoculante $2.5 \times 10^{9} \mathrm{cel} \mathrm{g}^{-1}$ suelo en $200 \mathrm{~g}$ de suelo en $30 \mathrm{~kg}$ de semilla, que obtuvo un promedio de 47.67 nódulos por planta (Tabla 1), valor que es mayor a los nódulos obtenidos en las observaciones mencionadas.

La inoculación en campo con cepas $R$. gallicum 8a3 y Ensifer meliloti 4H41 (aproximadamente $10^{8}$ cel planta $^{-1}$ ) en plántulas de $P$. vulgaris, incrementaron significativamente el número de nódulos que llegaron a 28 y 17 , respectivamente, al comparar con las plantas control (Trabelsi et al., 2011); estas cifras son menores al resultado más alto obtenido en esta investigación, pero con la mayor concentración de Rhizobium. Cabe señalar que el tratamiento inoculante $2.5 \times 10^{9} \mathrm{cel} \mathrm{g}^{-1}$ suelo tuvo una concentración aproximada de $4.78 \times 10^{6}$ células semilla ${ }^{-1}$, que alcanzó el mayor número de nódulos por planta, este dato está dentro del estándar mínimo de células por semilla recomendado por Lupwayi et al. (2000) que es $10^{5}$ para semillas grandes, como por ejemplo: soya, guisante y frejol. 
Porcentaje de nódulos efectivos por planta.

La infección en las raíces de las leguminosas por un simbionte adecuado de Rhizobium forma nódulos donde se realiza la fijación biológica de nitrógeno, la leghemoglobina es una proteína que se une al $\mathrm{O}_{2}$, es roja, contiene hierro y está presente en nódulos sanos fijadores de nitrógeno; en condiciones normales ni Rhizobium ni la leguminosa pueden fijar nitrógeno de manera independiente, se requiere de una interacción entre ellos (Madigan et al., 2000).

En el porcentaje de nódulos efectivos hubo diferencia significativa en los tratamientos, el tratamiento con la mayor concentración $\left(2.5 \times 10^{9} \mathrm{cel}\right.$ $\mathrm{g}^{-1}$ suelo) tuvo la mayor efectividad $84.02 \%$ y fue más efectivo que el tratamiento testigo fertilizado. Los tratamientos que no fueron inoculados también presentaron nódulos efectivos, como en el caso del control negativo, testigo fertilizado y testigo biológico con una efectividad del 38.65, 57.12 y $52.83 \%$, respectivamente, lo que evidencia la presencia de rizobios nativos, pero con una efectividad menor a la cepa inoculada en condiciones de campo (Tabla 2).

El porcentaje de nitrógeno en el análisis físico químico inicial de suelo fue bajo, esto pudiera permitir un desarrollo de rizobios nativos y la eficiente infectividad del inóculo agregado. El incremento de la disponibilidad de fósforo tiene un efecto positivo en el número de nódulos por planta, también en la forma de nódulos como su área activa; la eficiencia de la fijación de nitrógeno se incrementa después de fijar fósforo, una nodulación baja puede deberse a que la fertilización con $\mathrm{N}$ pudo ser por absorción de nitratos y amonio (Chmelíková \& Hejcman, 2012).

Zapata et al. (2014) obtuvieron porcentajes de nódulos efectivos que variaron entre 69.71 y $80.15 \%$ en maní (Arachis hipogaea L.) inoculado con cepas de Bradyrhizobium ( $\left.3 \times 10^{7} \mathrm{cel} \mathrm{mL}^{-1}\right)$, estos resultados son similares a los porcentajes obtenidos en esta investigación, pero con las concentraciones más altas (Tabla 2$) 84.02 \%\left(2.5 \times 10^{9}\right.$ cel g $^{-1}$ suelo) y $73.88 \%$ ( 2.5 x $10^{8}$ cel g ${ }^{-1}$ suelo).

Evaluaciones a cosecha de vainita.

En el rendimiento de vainita en $\mathrm{kg} \mathrm{ha}^{-1}$ se encontró una influencia del inoculante en los tratamientos inoculante $2.5 \times 10^{9} \mathrm{cel} \mathrm{g}^{-1}$ suelo y $2.5 \times 10^{8} \mathrm{cel} \mathrm{g}^{-1}$ suelo, en comparación con el control negativo y testigo

Tabla 2. Porcentaje de nódulos efectivos por planta para diferentes tratamientos aplicados en vainita variedad Jade.

\begin{tabular}{lc}
\hline Tratamientos & \% nódulos efectivos \\
\hline $2.5 \times 10 \mathrm{E} 7$ cel g suelo & $67.84 \mathrm{a}$ \\
$2.5 \times 10 \mathrm{E} 8$ cel g suelo & $73.88 \mathrm{a}$ \\
$2.5 \times 10 \mathrm{E} 9$ cel g suelo & $84.02 \mathrm{~b}$ \\
Control negativo & $38.65 \mathrm{c}$ \\
Testigo fertilizado & $57.12 \mathrm{~d}$ \\
Testigo biológico & $52.83 \mathrm{~d}$ \\
\hline Valores sin letras en común son significativamente \\
diferentes $(\mathrm{p}<0.05)$.
\end{tabular}

biológico (Tabla 3). Se pudo reemplazar el fertilizante químico urea, principalmente en el tratamiento inoculante $2.5 \times 10^{9} \mathrm{cel} \mathrm{g}^{-1}$ suelo, ya que no tuvo diferencia significativa con el testigo fertilizado, y generó una mayor influencia entre los tratamientos inoculados con $R$. etli. Investigaciones en campo demostraron que la biofertilización con cepas nativas seleccionadas de $R$. leguminosarum fueron capaces de reemplazar totalmente la fertilización química nitrogenada (Mulas et al., 2011).

Los tratamientos de inoculante $2.5 \times 10^{9} \mathrm{cel} \mathrm{g}^{-1}$ suelo y $2.5 \times 10^{8} \mathrm{cel} \mathrm{g}^{-1}$ suelo no tuvieron diferencias significativas en el rendimiento con el testigo fertilizado, estos resultados concuerdan con lo informado por Zapata et al. (2014) quienes encontraron que cepas fijadoras de nitrógeno comparadas con la fertilización nitrogenada para el cultivo de maní, fueron capaces de promover rendimientos iguales o superiores al obtenido con la aplicación de nitrógeno.

Asimismo, cepas de R. tropici inoculadas en frejol Carioca tuvieron productividades de granos similares a los fertilizados con $80 \mathrm{~kg} \mathrm{~N} \mathrm{ha}^{-1}$ (Otsubo et al., 2013), así como también se informan rendimientos de grano similares bajo fertilización con $\mathrm{N}$ e inoculación con Rhizobium (Grange et al., 2007). En contraste, Pereira et al. (2015) evidenciaron mayores rendimientos cuando se fertiliza con nitrógeno mineral en comparación con la inoculación con $R$. tropici SEMIA 4080 en frejol común 'BRS Pontal'. De igual manera, Otieno et al. (2009) inocularon Rhizobium en $P$. vulgaris L. cv GLP 2 y no obtuvieron un efecto significativo en el rendimiento en campo.

Una fertilización con $20 \mathrm{~kg} \mathrm{~N}^{-1}$ más inoculante con la cepa de $R$. tropici CIAT 899 (densidad de $10^{9} \mathrm{cel}$ $\mathrm{g}^{-1}$ de turba, $500 \mathrm{~g}$ para $50 \mathrm{~kg}$ semilla), se pudo obtener un rendimiento de $3339 \mathrm{Kg} \mathrm{ha}^{-1}$ de cultivo de frejol común, equivalente a la aplicación de hasta $160 \mathrm{~kg} \mathrm{~N}$ ha $^{-1}$ (Pelegrin et al., 2009); rendimiento similar al obtenido en esta investigación con la concentración más alta de inoculante $\left(2.5 \times 10^{9} \mathrm{cel} \mathrm{g}^{-1}\right.$ suelo $)$ que fue $3038.95 \mathrm{Kg} \mathrm{ha}^{-1}$.

En el rendimiento por planta (Tabla 3) hubo una influencia significativa de $R$. etli en los tratamientos 2.5 x $10^{9}$ cel g-1 $^{-1}$ suelo $(60.78 \mathrm{~g})$ y $2.5 \times 10^{8}$ cel g ${ }^{-1}$ suelo $(51.42 \mathrm{~g})$, la concentración más alta del inoculante 2.5 x $10^{9} \mathrm{cel} \mathrm{g}^{-1}$ suelo tuvo una mejor influencia en el rendimiento por planta entre los tratamientos inoculados. Estos resultados fueron similares a lo que informan Mulas et al. (2011) y Mulas et al. (2015), que observaron que la biofertilización con cepas seleccionadas de Rhizobium ( $3 \times 10^{8} \mathrm{cel} \mathrm{g}^{-1}$ turba) y la fertilización química con $\mathrm{N}$ estuvieron significativamente más altas en el rendimiento por planta, que el control no fertilizado. Trabelsi et al. (2011) refieren que la inoculación en campo de $P$. vulgaris con cepas de E. meliloti $4 \mathrm{H} 41$ y $R$. gallicum $8 \mathrm{a} 3$ obtuvieron un rendimiento por planta de $14 \mathrm{~g}$ y 22 $\mathrm{g}$, respectivamente, esto generó un incremento 
significativo, en comparación con las plantas control con una dosis aproximada de $10^{8}$ cel planta $^{-1}$; nuestros resultados evidencian valores mayores a estos mencionados, no obstante, con una concentración aproximada entre $10^{4}-10^{6}$ células por semilla.

En la longitud de vaina (Tabla 3 ) no se observó una influencia del inoculante en las tres concentraciones aplicadas en comparación con el control negativo y el testigo fertilizado, los valores más altos estuvieron entre 14.17 y $14.42 \mathrm{~cm}$ con la var. Jade. Esto concuerda con Barrios \& Siura (1999) que utilizaron diferentes concentraciones de biol en el cultivo de vainita (var. Bush Blue Lake 47) y tampoco encontraron diferencia significativa en la longitud de la vaina, obtuvieron un promedio de $12.97 \mathrm{~cm}$ y cuando aplicaron foliarmente biol al 10\% informaron menos de $12.90 \mathrm{~cm}$, estos resultados fueron menores a los que se encontraron en la presente investigación.

El nivel alto de potasio que se constató en el análisis inicial, pudo originar que no haya diferencia significativa en la longitud de vaina entre los tratamientos mencionados. Las plantas leguminosas tienen altos requerimientos en fósforo y potasio, caso contrario ocurre con el $\mathrm{N}$ mineral, ya que son capaces de fijar suficientes cantidades a través de la fijación biológica de N (Howieson et al., 2011). Estas plantas son sensibles a las deficiencias de fósforo, potasio y azufre, nutrientes que afectan de manera directa la fijación biológica de nitrógeno, e indirectamente el crecimiento de la leguminosa (Divito \& Sadras, 2014).

Un adecuado contenido de potasio en las plantas fijadoras de nitrógeno molecular por simbiosis, como las leguminosas, incrementa la actividad de la enzima nitrogenasa y la cantidad de nitrógeno molecular fijado dentro de los nódulos bacteriales (Kass, 1998). El potasio participa también en la osmorregulación, que es importante en la extensión celular y el movimiento de estomas (Hawkesford et al., 2012). Los parámetros de apariencia del tamaño como largo, ancho, peso, volumen de un producto son influenciados por la nutrición de la planta (Sørensen et al., 1995).

En cuanto al peso de la vaina (Tabla 3) no se observó una influencia de la concentración del inoculante en los tratamientos con R. etli $2.5 \times 10^{9}$ cel $\mathrm{g}^{-1}$ suelo (6.04 g), $2.5 \times 10^{8}$ cel g$^{-1}$ suelo (5.95 g) y 2.5 x $10^{7}$ cel $\mathrm{g}^{-1}$ suelo $(5.97 \mathrm{~g})$, ya que fueron estadísticamente iguales a los testigos y al control negativo. Asimismo, Barrios \& Siura (1999) no hallaron diferencia significativa en el peso de la vaina, obtuvieron resultados similares de $6.02 \mathrm{~g}$ con la variedad Bush Blue Lake 47 al aplicar diferentes concentraciones de biol foliar y al suelo.

Como ya se mencionó inicialmente se constató un nivel de potasio alto, debido a esto se agregó en el suelo una proporción menor durante la siembra. Al no haber diferencia significativa en el peso de vaina en los tratamientos evaluados, el potasio pudo tener efecto en el peso de los frutos. El potasio estimula la turgencia celular y actúa en gran parte como activador enzimático en los procesos físiológicos de las plantas, además, facilita el transporte de productos fotosintéticos, hacia sitios de almacenamiento o de crecimiento en semillas, tubérculos y frutas (Kass, 1998).

En el número de vainas por planta (Tabla 3) se encontró que las concentraciones $R$. etli $2.5 \times 10^{9} \mathrm{cel} \mathrm{g}^{-}$ 1 suelo y $2.5 \times 10^{8}$ cel $\mathrm{g}^{-1}$ suelo no tuvieron una diferencia significativa frente al testigo fertilizado, sin embargo, sí se observó una influencia del inoculante en estas concentraciones en comparación con los tratamientos inoculante $2.5 \times 10^{7} \mathrm{cel} \mathrm{g}^{-1}$ suelo, control negativo y testigo biológico.

Los resultados en el número de vainas por planta fueron de $12.19\left(2.5 \times 10^{9} \mathrm{cel} \mathrm{g}^{-1}\right.$ suelo) y 12.05 ( $2.5 \mathrm{x}$ $10^{8}$ cel g-1 suelo), mientras que Otieno et al. (2009) obtuvieron una media de 9.3 (en lluvias largas) y 8.2 (lluvias cortas) vainas por planta en $P$. vulgaris $\mathrm{L}$. cv GLP 2 inoculado con Rhizobium.

La inoculación en $P$. vulgaris $L$. con cepas de Rhizobium LCS0306, LBM1123 y ZBM1008 en concentraciones de $3 \times 10^{8}$ cel $\mathrm{g}^{-1}$ de turba y la fertilización indujeron un alto número de vainas por planta, su concentración fue de $1 \times 10^{6}$ Rhizobium por semilla (Mulas et al., 2015). En esta investigación el tratamiento $2.5 \times 10^{9}$ cel $\mathrm{g}^{-1}$ suelo, tuvo una concentración aproximada de $4.78 \times 10^{6}$ Rhizobium por semilla, que también influenció en el número de vainas por planta.

Diferente fue lo obtenido por Otsubo et al. (2013) que trabajaron en diferentes linajes del grupo Frejol Carioca inoculados con dos cepas de R. tropici $\left(10^{9} \mathrm{cel}\right.$ $\mathrm{g}^{-1}$ de turba y $500 \mathrm{~g}$ de turba que se aplicaron para 50 $\mathrm{kg}$ de semilla), no hallaron diferencias en el número de vainas por planta en tratamientos inoculados o fertilizados con nitrógeno en comparación con el control.

Tabla 3. Evaluaciones en cosecha para diversos tratamientos aplicados en vainita variedad Jade.

\begin{tabular}{lccccc}
\hline Tratamientos & \multicolumn{1}{c}{$\begin{array}{c}\text { Rendimiento } \\
\mathrm{kg} \mathrm{ha}^{-1}\end{array}$} & $\begin{array}{c}\text { Rendimiento } \\
\mathrm{g} \mathrm{planta}^{-1}\end{array}$ & $\begin{array}{c}\text { Longitud de vaina } \\
\mathrm{cm}\end{array}$ & $\begin{array}{c}\text { Peso de vaina } \\
\mathrm{g}\end{array}$ & $\begin{array}{c}\text { Número de vainas } \\
\text { por planta N }^{\circ}\end{array}$ \\
\hline $2.5 \times 10^{7} \mathrm{cel} \mathrm{g}^{-1}$ suelo & $1978.25 \pm 179.72 \mathrm{bc}$ & $39.57 \pm 3.59 \mathrm{bc}$ & $14.17 \pm 0.52 \mathrm{ab}$ & $5.97 \pm 0.40 \mathrm{ab}$ & $7.73 \pm 0.67 \mathrm{~b}$ \\
$2.5 \times 10^{8} \mathrm{cel} \mathrm{g}^{-1}$ suelo & $2570.87 \pm 504,00 \mathrm{ab}$ & $51.42 \pm 10.08 \mathrm{ab}$ & $14.25 \pm 0.42 \mathrm{ab}$ & $5.95 \pm 0.18 \mathrm{ab}$ & $12.05 \pm 2.26 \mathrm{a}$ \\
$2.5 \times 10^{9} \mathrm{cel} \mathrm{g}^{-1}$ suelo & $3038.95 \pm 189.75 \mathrm{a}$ & $60.78 \pm 3.80 \mathrm{a}$ & $14.17 \pm 0.40 \mathrm{ab}$ & $6.04 \pm 0.32 \mathrm{ab}$ & $12.19 \pm 1.97 \mathrm{a}$ \\
Control - & $1477.58 \pm 121.09 \mathrm{~cd}$ & $29.55 \pm 2.42 \mathrm{~cd}$ & $13.80 \pm 0.05 \mathrm{bc}$ & $5.73 \pm 0.17 \mathrm{~b}$ & $5.80 \pm 0.30 \mathrm{bc}$ \\
Testigo fertilizado & $3172.80 \pm 630.05 \mathrm{a}$ & $63.46 \pm 12.60 \mathrm{a}$ & $14.42 \pm 0.09 \mathrm{a}$ & $6.33 \pm 0.20 \mathrm{a}$ & $12.85 \pm 2.36 \mathrm{a}$ \\
Testigo biológico & $1124.60 \pm 178.69 \mathrm{~d}$ & $22.49 \pm 3.57 \mathrm{~d}$ & $13.54 \pm 0.28 \mathrm{c}$ & $5.50 \pm 0.37 \mathrm{~b}$ & $4.40 \pm 0.69 \mathrm{c}$ \\
\hline
\end{tabular}

Letras distintas en la misma columna indican que los valores difieren significativamente. ANDEVA, test Duncan (p<0.05). 
La concentración $2.5 \times 10^{9}$ cel $\mathrm{g}^{-1}$ suelo del inoculante permitió la mayor probabilidad de infección y un mejor efecto en campo, ésta fue similar a las concentraciones que aplicaron Otsubo et al. (2013) y Pelegrin et al. (2009) en investigaciones sobre Phaseolus en climas tropicales como en Brasil; es así que se requirió una concentración similar para que el inoculante pueda tener un efecto en suelos pobres en materia orgánica como es el suelo de la costa sur peruana y con un clima subtropical árido.

\section{Conclusiones.}

1. El tratamiento inoculado con una concentración de $2.5 \times 10^{9}$ cel g $^{-1}$ suelo generó el mayor número de nódulos totales con un promedio de $47.67 \mathrm{y}$ una efectividad de $84.02 \%$.

2. El tratamiento anteriormente mencionado produjo una mayor influencia en el rendimiento por hectárea, rendimiento por planta y número de vainas por planta, al mismo tiempo que no tuvo diferencia significativa al ser comparado con el testigo fertilizado.

\section{Agradecimientos.}

Los autores agradecen al INPREX, a la Escuela de Biología-Microbiología de la Facultad de Ciencias de la Universidad Nacional Jorge Basadre Grohmann, a la Dra. Bertha Soriano Bernilla de la Universidad Nacional de Trujillo, quien proporcionó la cepa bacteriana que permitió iniciar esta investigación.

\section{Literatura citada.}

Albareda M., Rodríguez-Navarro D.N., Camacho M. \& Temprano F.J. 2008. Alternatives to peat as a carrier for rhizobia inoculants: Solid and liquid formulations. Soil Biology \& Biochemistry. 40(11): 2771-2779.

Aserse A.A., Räsänen L.A., Assefa F., Hailemariam A. \& Lindström K. 2012. Phylogeny and genetic diversity of native rhizobia nodulating common bean (Phaseolus vulgaris L.) in Ethiopia. Systematic and Applied Microbiology. 35(2): 120-131.

Barrios F. \& Siura S. 1999. Efecto de diferentes concentraciones de biol aplicados foliarmente y al suelo en el cultivo de vainita (Phaseolus vulgaris L.). Páginas 91-103. En: I. Arning, y H. Velásquez (editores) V Congreso Nacional RAAA, Participación Ciudadana para la Institucionalidad de la Agricultura Ecológica. 2-6 de octubre del 2001. Lima, Perú. Red de Acción en Alternativas al Uso de Agroquímicos (RAAA), Lima, Perú.

Beebe S., Rengifo J., Gaitan E., Duque M.C. \& Tohme J. 2001. Diversity and origin of Andean landraces of common bean. Crop Sci. 41(3): 854-862.

Berton J.J.F., Santos J.C.P., Coehlo C.M.M. \& Klauberg F.O. 2008. Effect of inoculation associated to leaf sprayed $\mathrm{Co}+\mathrm{Mo}$ on the yield and grain nutrients in common bean (Phaseolus vulgaris L). Braz. Arch. Biol. Technol. 51(6): 1089-1096.

Bharti V., Mehta A. \& Kumar A. 2015. Advances in the development of microbial biofertilizers as a tool for sustainable agriculture. Páginas 189-208. En: Nova
Science Publishers (editores) Microbes in soil and their agricultural prospects. Dr. Harisingh Gour University (Central University), Sagar, MP, India.

CIAT. 1988. Simbiosis leguminosa- rizobio: Manual de métodos de evaluación selección y manejo agronómico. Centro Internacional de Agricultura Tropical, Cali, Colombia.

Chmelíková L., \& Hejcman M. 2012. Effect of nitrogen, phosphorus and potassium availability on emergence, nodulation and growth of acidicole Trifolium arvense $\mathrm{L}$. in alkaline soil. Flora - Morphology, Distribution, Functional Ecology of Plants. 207(11): 805-811.

Dardanelli M.S., Fernández de Córdoba F.J., Espuny M.R., Rodríguez Carvajal M.A., Soria Díaz M.E., Gil Serrano A.M., Okon Y. \& Megías M. 2008. Effect of Azospirillum brasilense coinoculated with Rhizobium on Phaseolus vulgaris flavonoids and Nod factor production under salt stress. Soil Biology \& Biochemistry. 40(11): 2713-2721.

Deaker R., Roughley R.J. \& Kennedy I.R. 2004. Legume seed inoculation technology-a review. Soil Biology \& Biochemistry. 36(8): 1275-1288.

Divito G.A. \& Sadras V.O. 2014. How do phosphorus, potassium and sulphur affect plant growth and biological nitrogen fixation in crop and pasture legumes? A metaanalysis. Field Crops Research. 156(Supplement C): 161171.

Ferrera-Cerrato R., González-Chávez M.C. \& RodríguezMendoza M.N. 1993. Manual de agromicrobiología. Ed. Trillas S. A., México.

Frioni L. 1999. Procesos microbianos. Editorial de la Fundación Nacional de Río Cuarto, Argentina.

Grange L., Hungria M., Graham P.H. \& Martínez-Romero E. 2007. New insights into the origins and evolution of rhizobia that nodulate common bean (Phaseolus vulgaris) in Brazil. Soil Biology and Biochemistry. 39(4): 867-876.

Grant W.D. \& Long P. 1989. Microbiología ambiental. Editorial Acribia S. A. Zaragoza, España.

Hawkesford M., Horst W., Kichey T., Lambers H., Schjoerring J., Skrumsager M.I. \& White P. 2012. Part I Nutritional physiology, functions of macronutrients Chapter 6. Página 135 (abstract). En: P. Marschner (editor) Marschner's mineral nutrition of highter plants. Germany.

Herridge D.F., Peoples M.B. \& Boddey R.M. 2008. Global inputs of biological nitrogen fixation in agricultural systems. Plant and Soil. 311(1): 1-18.

Howieson J.G., Ballard R.A., Yates R. J. \& Charman N. 2011. Selecting improved Lotus nodulating rhizobia to expedite the development of new forage species. Plant and Soil. 348(1): 231-243.

Kass D.C.L. 1998. Fertilidad de suelos. Editorial EUNED, San José, Costa Rica.

Kloepper J.W., Hu C.H., Burkett-Cadena M., Liu K., Xu J. \& McInroy J. 2012. Increased populations of deleterious fluorescent pseudomonads colonizing rhizomes of leatherleaf fern (Rumohra adiantiformis) and expression of symptoms of fern distortion syndrome after application of Benlate systemic fungicide. Microorganisms and the Sustainable Management of Soil. 61(Supplement C): 236-246.

Lupwayi N.Z., Olsen P.E., Sande E.S., Keyser H.H., Collins M.M., Singleton P.W. \& Rice W.A. 2000. Inoculant quality and its evaluation. Field Crops Research. 65(2): 259-270. 
Madigan M.T., Martinko J.M. \& Parker J. 2000. Brock biología de los microorganismos. Octava Edición. Ed. Prentice Hall, Madrid, España.

Mårtensson A.M. 1992. Effects of agrochemicals and heavy metals on fast-growing rhizobia and their symbiosis with small-seeded legumes. Soil Biology and Biochemistry. 24(5): 435-445.

Ministerio de Agricultura y Riego. 2014. Anuario producción agrícola 2014. Ministerio de Agricultura, Lima, Perú.

Mulas D., García-Fraile P., Carro L., Ramírez-Bahena M.H., Casquero P., Velázquez E., González-Andrés F. 2011. Distribution and efficiency of Rhizobium leguminosarum strains nodulating Phaseolus vulgaris in Northern Spanish soils: Selection of native strains that replace conventional $\mathrm{N}$ fertilization. Soil Biology \& Biochemistry. 43(11): 2283-2293.

Mulas D., Seco V., Casquero P.A., Velázquez E. \& GonzálezAndrés F. 2015. Inoculation with indigenous Rhizobium strains increases yields of common bean (Phaseolus vulgaris L.) in northern Spain, although its efficiency is affected by the tillage system. Symbiosis. 67(1): 113-124.

Otsubo A.A., Brito O.R. \& Mercante F.M. 2013. Productivity and nodulation of promising lineages of the Carioca bean group inoculated with Rhizobium tropici or supplemented with nitrogen fertilizer. Ciências Agrárias. 34(6): $2763-$ 2776.

Otieno P.E., Muthomi J.W., Chemining'wa G.N. \& Nderitu J.H. 2009. Effect of rhizobia inoculation, farm yard manure and nitrogen fertilizer on nodulation and yield of food grain legumes. Journal of Biological Sciences. 9(4): 326-332.

Pelegrin R.D., Mercante F.M., Otsubo. I.M.N. \& Otsubo A.A. 2009. Response of common bean crop to nitrogen fertilization and Rhizobium inoculation. R. Bras. Ci. Solo. 33(1): 219-226.

Peoples M.B., Brockwell J., Herridge D.F., Rochester I.J., Alves B.J.R., Urquiaga S., Boddey R.M., Dakora F.D., Bhattarai S., Maskey S.L., Sampet C., Rerkasem B., Khan D.F., Hauggaard-Nielsen H. \& Jensen E.S. 2009. The contributions of nitrogen-fixing crop legumes to the productivity of agricultural systems. Symbiosis. 48(1): 117.

Peoples M.B. \& Herridge D.F. 1990. Nitrogen fixation by legumes in tropical and subtropical agriculture. Páginas
155-223. En: N. C. Brady (editores) Advances in agronomy Vol. 44. Academic Press, New York.

Pereira H.S., Melo L.C., Faria L.C.D., Ferreira E.P.D.B., Mercante F.M., Wendland A. \& Souza T.L.P.O.D. 2015. Common bean elite lines cultivated under nitrogen fertilization and inoculation with Rhizobium tropici. Ciência Rural. 45(12): 2168-2173.

Rodiño P.A., Santalla M., De Ron A.M. \& Drevon J.J. 2010. Co-evolution and migration of bean and rhizobia in Europe. Páginas 171-188. En: E. Lichtfouse (editores) Sociology, Organic Farming, Climate Change and Soil Science. Dordrecht Springer, Netherlands.

SENAMHI. 2014. Información meteorológica Tacna. Servicio Nacional de Meteorología e Hidrología del Perú (SENAMHI), Tacna, Perú.

Silvester R. 1983. Fijación biológica de nitrógeno por leguminosas: aspectos agronómicos relacionados con su nodulación de Rhizobium. Suelos Ecuatoriales. 13(2): 2835.

Sørensen J.N., Johansen A.S. \& Kaack K. 1995. Marketable and nutritional quality of leeks as affected by water and nitrogen supply and plant age at harvest. J. Sci. Food Agric. 68(3): 367-373.

Statpoint Technologies INC. 2010. Statgraphics ${ }^{\circledR}$ Centurion XVI manual de usuario. Estados Unidos de América.

Trabelsi D., Mengoni A., Ben Ammar H. \& Mhamdi R. 2011. Effect of on-field inoculation of Phaseolus vulgaris with rhizobia on soil bacterial communities. FEMS Microbiology Ecology. 77(1): 211-222.

Vincent J.M. 1970. A manual for the practical study of rootnodule bacteria. International Biological Programme Handbook $\mathrm{N}^{0} 15$. Blackwell Scientific Publications, Oxford, UK.

Zapata N., Vargas M., Gerding M. \& Chandía M. 2014. Inoculación de maní (Arachis hipogaea L.) con diferentes cepas del género Bradyrhizobium y su efecto sobre el crecimiento y rendimiento del cultivo. Chilean Journal of Agricultural \& Animal Sciences, ex Agro-Ciencia. 30(1): 57-64.

Zúñiga D.D. 2012. Manual de microbiología agrícola: Rhizobium, PGPR, indicadores de fertilidad e inocuidad. Universidad Nacional Agraria La Molina. Ed. María Olaya, Lima-Perú.

${ }^{1}$ Universidad Nacional Jorge Basadre Grohmann, Av. Miraflores S/N (Ciudad Universitaria), Apartado Postal 316 Tacna-Perú, vliliana007@hotmail.com.

${ }^{2}$ Universidad Privada de Tacna, Campus Capanique, Av. Jorge Basadre Grohmann s/n Pocollay - Tacna, Apartado postal 126 Tacna-Perú, claudiavck@hotmail.com.

${ }^{3}$ Universidad Nacional Jorge Basadre Grohmann, Av. Miraflores S/N (Ciudad Universitaria), Apartado Postal 316Tacna-Perú, paulmedinab@hotmail.com.

${ }^{4}$ Universidad Nacional Jorge Basadre Grohmann, Av. Miraflores S/N (Ciudad Universitaria), Apartado Postal 316 Tacna-Perú, daladiercastillo@hotmail.com. 